\title{
Determination of antimicrobial MIC by paper diffusion method
}

\author{
M. S. SHAFI
}

From the Department of Microbiology, Central Middlesex Hospital, London NW10 7NS

SYNOPSIS Because they are cumbersome, tests to determine the quantitative susceptibility of organisms to antimicrobial drugs are not performed routinely in many diagnostic laboratories. This paper describes a simple method of incorporating the antimicrobial drug in agar. It is an adaptation of the Rolinson and Russell technique which allows the determination of minimum inhibitory concentrations (MIC) of antimicrobial drugs for a large number of organisms. Results are comparable with those obtained when the standard agar dilution method is used. Strains of aerobic Gram-negative bacilli were tested by both methods using ampicillin ( 86 strains), cephaloridine (72 strains), trimethoprim (72 strains), and gentamicin (72 strains). Of the 302 tests thus performed, a difference in MIC of more than one double dilution was noted in only 11 tests. With one strain of Pseudomonas aeruginosa, however, it was not possible to detect ampicillin resistance by the method described in this paper.

It is common practice to report the susceptibility of an organism isolated from a patient and considered to be of clinical significance as either 'sensitive' or 'resistant' to a particular antimicrobial drug. Laboratory methods for assessing the susceptibility of an organism to such drugs vary. Broadly, they fall into two groups - disc diffusion tests and dilution tests. Because they are simple to perform, disc diffusion tests are used routinely in many diagnostic laboratories.

Several studies have been performed to compare results of antimicrobial sensitivity tests obtained by different laboratories on strains of organisms sent either as simulated clinical specimens or as pure cultures (Institute of Medical Laboratory Technology, 1960; Association of Clinical Pathologists, 1965; College of Pathologists of Australia, 1968; Castle and Elstub, 1971). These studies have shown a wide range of discrepant results and this has given cause for concern.

In recent years attempts have been made to standardize disc diffusion tests and to interpret zone diameters in terms of minimum inhibitory concentrations (MIC) of the antimicrobial substance (Bauer et al, 1966; Ericsson and Sherris, 1971). Such methods require rigid standardization and, when performed as recommended, are time consuming and laborious.

Received for publication 4 July 1975
Although the Stokes method of disc sensitivity testing (Stokes, 1968) aims at controlling all variables including the performance of the disc, it gives only a qualitative indication of the susceptibility of an organism to an antimicrobial drug.

Standard methods for determining the MIC of antimicrobial drugs are time consuming and are therefore not performed routinely. Rolinson and Russell (1972), however, described a method of sensitivity testing by means of filter paper impregnated with known amounts of drug which diffused into a shallow layer of agar. This paper describes an adaptation of the Rolinson and Russell technique which allows quantitative estimation of drug susceptibility in routine microbiology and will be referred to as the paper diffusion method.

\section{Material and Methods}

DETERMINATION OF MIC BY THE AGAR

DILUTION 'STANDARD' METHOD

Solutions containing 40,80,120,160,200, and 400 $\mu \mathrm{g}$ ampicillin or cephaloridine per $\mathrm{ml}$ and $5,10,20$, 40 , and $80 \mu \mathrm{g}$ trimethoprim or gentamicin per $\mathrm{ml}$ were prepared in distilled water. Two $\mathrm{ml}$ aliquots of each solution were stored at $-20^{\circ} \mathrm{C}$ and were used within two weeks of preparation. The ampicillin, cephaloridine, and gentamicin were of the kind intended for therapeutic use by injection. Trimetho- 
prim lactate was obtained from Burroughs Wellcome \& Company. Plates were prepared by mixing $1 \mathrm{ml}$ antimicrobial solution with $19 \mathrm{ml}$ molten DST agar (Oxoid) at a temprature of less than $50^{\circ} \mathrm{C}$. The final concentrations of the drug in agar were $2,4,6,8$, 10 , and $20 \mu \mathrm{g} / \mathrm{ml}$ for ampicillin and cephaloridine and $0.25,0.5,1,2$, and $4 \mu \mathrm{g} / \mathrm{ml}$ for trimethoprim and gentamicin. Approximately $0.003 \mathrm{ml}$ of a 4hour broth culture of each test organism was applied to the agar surface by means of a multipoint inoculator ${ }^{1}$. Results were recorded after overnight incubation at $37^{\circ} \mathrm{C}$. The MIC of each drug was taken as the least concentration completely inhibiting growth.

\section{PAPER DIFFUSION METHOD}

Preparation of papers

Absorbent papers $(9 \times 9 \mathrm{~cm})$ impregnated with 40 , $80,120,160,200$, and $400 \mu \mathrm{g}$ ampicillin were obtained from Mast Laboratories.

Samples of these absorbent papers were investigated by eluting the drug from them into distilled water, and assays were performed by the plate diffusion method to ascertain that the papers contained the intended amounts of ampicillin.

Cephaloridine, trimethoprim, and gentamicin papers were prepared in the laboratory, Initially, tests were carried out to determine whether a constant volume of water is absorbed by filter paper of a given size. For this purpose, Whatman's No. 1 filter paper $9 \times 9 \mathrm{~cm}$ square (sterilized by autoclaving) were weighed. After immersing the paper in water, excess water was removed by lightly blotting over the surface of dry absorbent paper. The filter paper was weighed again to determine the amount of water held by it. This procedure was repeated with 10 papers. The weight of water (and hence the volume) held by each paper ranged from 1.05 to $1.09 \mathrm{~g}$.

Since by this method each paper was found to hold approximately $1 \mathrm{ml}$ water, papers were prepared by immersing them in cephaloridine, trimethoprim, and gentamicin solutions of appropriate concentrations. After removal of the excess solution as described above, the filter papers were dried in a 1Obtained from Denby Instruments Ltd, Bolney. Sussex laminar flow cabinet for 3-4 hours and stored at ${ }^{\circ}$ $4^{\circ} \mathrm{C}$ over anhydrous calcium chloride in a desiccator. The papers were used within two weeks of preparation.

\section{Determination of MIC by the Paper Diffusion Method}

Tests were carried out on square plates $10 \times 10 \mathrm{~cm}$ containing $20 \mathrm{ml}$ DST agar (Oxoid). Filter papers impregnated with antimicrobial drug were placed of on the surface of the agar. Rolinson and Russell $\overrightarrow{0}$ (1972) observed that many of the commonly used $\overrightarrow{\mid}$ antibiotics required $1 \frac{1}{2}$ to 4 hours for uniform $\omega$ diffusion of the drug from the paper into the agar.

Plates were therefore left at room temperature for 4 hours to allow diffusion of the drug. The 9 expected concentrations of drug in agar were for $\vec{N}$ ampicillin and cephaloridine $2,4,6,8,10$, and 20 $\mu \mathrm{g} / \mathrm{ml}$ and for trimethoprim and gentamicin 0.25 , $0.5,1,2$, and $4 \mu \mathrm{g} / \mathrm{ml}$. Papers were then removed 음 and each plate was inoculated with up to 20 bacterial strains. Similar inocula were used for both the paper diffusion and agar dilution tests.

Preliminary tests with five strains of organisms had shown that the drug diffused uniformly into the $\mathbb{D}$ agar. To do so each of the five strains was inoculated $\vec{\varphi}$ on four different parts of plates containing varios concentrations of ampicillin. In some plates the ampicillin had been introduced by adding it to the molten agar and in others by the paper diffusion method.

One hundred strains of Gram-negative bacteria $\stackrel{2}{\circ}$ isolated from clinical specimens were tested by both $\stackrel{\mathbb{Q}}{\circ}$ the standard method and the paper diffusion method. $\overrightarrow{0}$ Eighty-six of these strains were tested with ampicillin 3 whereas 72 strains were used to perform the tests with cephaloridine, trimethoprim, and gentamicin. Escherichia coli NCTC 10418 and two other strains of Esch. coli (Nos 3669/74 and 31799/74) isolated from clinical specimens were included as controls with each batch of tests. An additional control strain of Klebsiella aerogenes (NCTC 8172) was included in tests with cephaloridine, trimethoprim, and gentamicin.

\begin{tabular}{|c|c|c|c|c|c|}
\hline & \multicolumn{5}{|l|}{ Esch. coli } \\
\hline & NCTC 10418 & $38076 / 74$ & $33874 / 74$ & $38275 / 74$ & $38342 / 74$ \\
\hline MIC by standard method $(\mu \mathrm{g} / \mathrm{ml})$ & $\begin{array}{l}\leqslant 2 \\
\leqslant 2 \\
\leqslant 2 \\
\leqslant 2\end{array}$ & $\begin{array}{l}4 \\
4 \\
4 \\
4\end{array}$ & $\begin{array}{l}4 \\
4 \\
4 \\
4\end{array}$ & $\begin{array}{l}6 \\
6 \\
6 \\
6\end{array}$ & $\begin{array}{l}8 \\
8 \\
8 \\
8\end{array}$ \\
\hline $\begin{array}{l}\text { MIC by paper diffusion method } \\
(\mu g / m l)\end{array}$ & $\begin{array}{l}\leqslant 2 \\
\leqslant 2 \\
\leqslant 2 \\
\leqslant 2\end{array}$ & $\begin{array}{l}4 \\
4 \\
4 \\
4\end{array}$ & $\begin{array}{r}4 \\
4 \\
4 \\
\leqslant 2\end{array}$ & $\begin{array}{l}4 \\
4 \\
4 \\
4\end{array}$ & $\begin{array}{l}4 \\
4 \\
4 \\
4\end{array}$ \\
\hline
\end{tabular}

Table I Variability of ampicillin MIC for five strains by inoculating different parts of the sample plate 


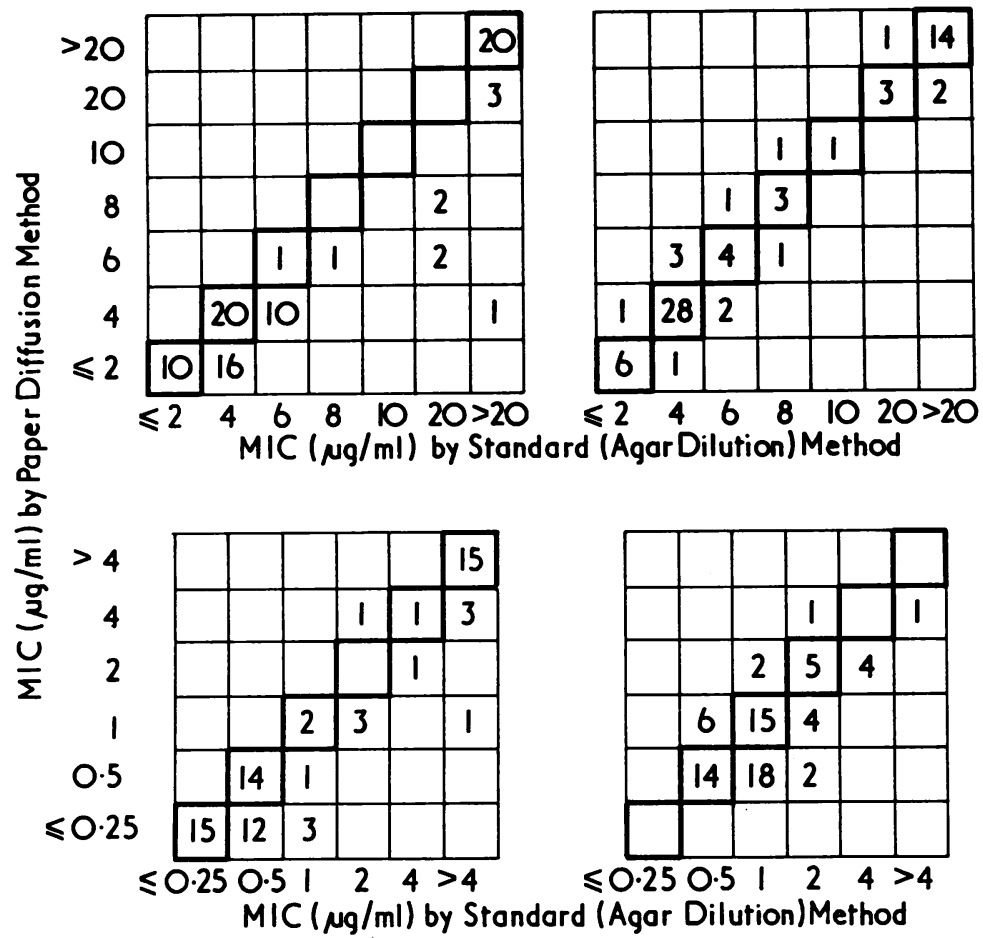

Figure Comparison of paper diffusion method with standard (agar dilution) method: MIC determination of ampicillin (top left), cephaloridine (top right), trimethoprim (bottom left), and gentamicin (bottom right).

\begin{tabular}{|c|c|c|c|c|c|c|c|c|c|}
\hline & \multirow{3}{*}{$\begin{array}{l}\text { No. of Times } \\
\text { tested }\end{array}$} & \multicolumn{8}{|c|}{ No. of Times Strains showing MIC $(\mu \mathrm{g} / \mathrm{ml})$} \\
\hline & & \multicolumn{4}{|c|}{ Paper Diffusion Method } & \multicolumn{4}{|c|}{ Standard Method } \\
\hline & & $\leqslant 2$ & 4 & 6 & 8 & $\leqslant 2$ & 4 & 6 & 8 \\
\hline \multicolumn{10}{|l|}{ Ampicillin } \\
\hline Esch. coli NCTC 10418 & 7 & 7 & & & & 7 & & & \\
\hline Esch, coli $3669 / 74$ & 7 & & 7 & & & & 5 & 2 & \\
\hline Esch. coli 31799/74 & 7 & 2 & 5 & & & & 7 & & \\
\hline \multicolumn{10}{|l|}{ Cephaloridine } \\
\hline Esch. coli NCTC 10418 & 6 & & 5 & 1 & & & 6 & & \\
\hline Klebsiella NCTC 8172 & 6 & 2 & 3 & 1 & & 2 & 3 & 1 & \\
\hline Esch. coli $3669 / 74$ & 6 & 1 & 4 & 1 & & 1 & 4 & 1 & \\
\hline Esch. coli 31799/74 & 5 & & 5 & & & & 5 & & \\
\hline
\end{tabular}

Table II Day-to-day variation in MIC of ampicillin and cephaloridine for the control strains

\begin{tabular}{|c|c|c|c|c|c|c|c|c|c|}
\hline & \multirow{3}{*}{$\begin{array}{l}\text { No of Times } \\
\text { tested }\end{array}$} & \multicolumn{8}{|c|}{ No. of Times Strains showing MIC $(\mu \mathrm{g} / \mathrm{ml})$} \\
\hline & & \multicolumn{4}{|c|}{ Paper Diffusion Method } & \multicolumn{4}{|c|}{ Standard Method } \\
\hline & & $<0.25$ & 0.5 & 1 & 2 & $<0 \cdot 25$ & 0.5 & 1 & 2 \\
\hline $\begin{array}{l}\text { Trimethoprim } \\
\text { Esch. coli NCTC } 10418 \\
\text { Klebsiella NCTC } 8172 \\
\text { Esch. coli } 3669 / 74 \\
\text { Esch. coli } 31799 / 74 \\
\text { Gentamicin }\end{array}$ & $\begin{array}{l}6 \\
6 \\
6 \\
6\end{array}$ & $\begin{array}{l}6 \\
6 \\
5 \\
1\end{array}$ & $\begin{array}{l}1 \\
5\end{array}$ & & & $\begin{array}{l}6 \\
6 \\
5\end{array}$ & $\begin{array}{l}1 \\
2\end{array}$ & 4 & \\
\hline $\begin{array}{l}\text { Esch. coli NCTC } 10418 \\
\text { Klebsiella NCTC } 8172 \\
\text { Esch. coli } 3669-74 \\
\text { Esch. coli } 31799 / 74\end{array}$ & $\begin{array}{l}6 \\
6 \\
6 \\
6\end{array}$ & & $\begin{array}{l}5 \\
6 \\
2 \\
3\end{array}$ & $\begin{array}{l}1 \\
4 \\
3\end{array}$ & & & $\begin{array}{l}6 \\
5 \\
1\end{array}$ & $\begin{array}{l}1 \\
6 \\
5\end{array}$ & \\
\hline
\end{tabular}

Table III Day-to-day variation in MIC of trimethoprim and gentamicin for the control strains 


\section{Results}

Table I shows the MIC of ampicillin for five strains of organisms which were inoculated on four different parts of each plate. For each strain tested the variation in MIC for the paper diffusion method was not significantly different from that for the agar dilution method. This indicates that the antibiotic in the paper diffused uniformly into the agar. Although the MIC for the strains 38275/74 and $38342 / 74$ was different by each of the two methods the difference was not more than one double dilution. The day-to-day variation in results of the control organisms included with each batch of tests is shown in tables II and III. Again the variability in MIC for each strain by the agar dilution method and by the paper diffusion method does not differ significantly.

A comparison of MIC is shown in the figure. None of the 72 strains tested against cephaloridine showed a difference in MIC of more than one double dilution. Only two of the 72 strains tested against gentamicin showed a difference in MIC of more than one double dilution while four strains showed such a difference with tests using trimethoprim. Of the 86 strains tested against ampicillin, five showed a difference in MIC of more than one double dilution. One of these five, a mucoid strain of Pseudomonas aeruginosa isolated from the sputum of a patient with bronchiectasis, showed the MIC of ampicillin to be $4 \mu \mathrm{g} / \mathrm{ml}$ for the paper diffusion method but $>20 \mu \mathrm{g} / \mathrm{ml}$ for the agar dilution method. The discrepancy was reproducible when tests were repeated. When this strain was tested by the broth dilution method the MIC was $62.5 \mu \mathrm{g} / \mathrm{ml}$ ampicillin. Clearly this strain was resistant to ampicillin and the result by the paper diffusion method was misleading. Investigation did not reveal any inhibitory substance in the paper impregnated with ampicillin.

\section{Discussion}

The disc diffusion method for sensitivity testing is simple to perform but does not give a quantitative assessment of susceptibility unless cumbersome standardization procedures are adopted. The simplicity of the test is then lost.

Ideally antimicrobial treatment should be based on the knowledge of two features, first, the relevant organism's susceptibility to the drugs available, and, second, the amount of the drug attainable at the site of infection. Information on the first of these features is not usually available in quantitative terms because methods suitable for routine use are not available. The agar dilution method (here described as the standard method) for determining the MIC is generally accepted as reliable but it is not commonly used in clinical laboratories because it is technically cumbersome. Furthermore, mistakes in the addition of drugs to media are readily made and difficult to recognize. The report of the international collaborative study (Ericsson and Sherris, 1971) suggested that, if used with the aid of semimechanized procedures, dilution tests are fully acceptable for routine methods. However, the need to simplify the incorporation of drugs into agar was emphasized. To achieve this they suggested that the availability of ampoules containing appropriate amounts of freezedried drug would be helpful.

In this study, consideration has been given to the feasibility of determining the MIC of a large number of strains using a simple method of incorporating the drug in agar. The paper diffusion method is easy to perform and the results obtained are similar to those obtained when the conventional agar dilution method is used. The concentrations of antimicrobia drugs used in the tests might be chosen either to give a comprehensive range for research purposes or a limited range so that strains tested might be classified for clinical purposes as sensitive, resistant or intermediate. Control strains of different MIG should be included in each batch of tests so as to check the lower, intermediate, and higher concen tration of each antimicrobial drug.

I should like to thank Dr. C. E. D. Taylor and Dr. D. A. McSwiggan for their help and encouragement and Mr. Philippe Wong Kai In for technical assistance.

\section{References}

Association of Clinical Pathologists (1965). Report on antibiotic sensitivity test trial organized by the Bacteriology Committee of the Association of Clinical Pathologists. J. clin. Path., 18, 1-5.

Bauer, A. W., Kirby, W. M. M., Sherris, J. C., and Turck, M. (1966). Antibiotic susceptibility testing by a standardized single disk method. Amer. J. clin. Path., 45, 493-496.

Castle, A. R. and Elstub, J. (1971). Antibiotic sensitivity testing: a survey undertaken in September 1970 in the United Kingdom. J. clin. Path., 24, 773-778.

College of Pathologists of Australia (1968). A survey of antibiotic sensitivity testing. Med.J. Aust., 2, 171-172.

Ericsson, H. M. and Sherris, J. C. (1971). Antibiotic sen-S sitivity testing: report of an international collaborative $\mathrm{N}$ study. Acta path. microbiol. scand., B Suppl., No. 217.

Institute of Medical Laboratory Technology (1960).'A survey $\omega$ of antibiotic sensitivity tests. J. med. Lab. Technol., 17,

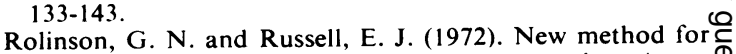
antibiotic susceptibility testing. Antimicrob. Agents Chemother., 2, 51-56.

Stokes, E. J. (1968). Clinical Bacteriology, 3rd edition, p. 179. Arnold, London. 